\title{
Studies on Clarification of Coal Washery Effluent Using Polymeric Flocculants and Settling Kinetics
}

\section{Sarika Narayanrao Pimpalkar ( $\sim$ sarika@iitism.ac.in )}

IIT (ISM): Indian Institute of Technology https://orcid.org/0000-0002-3653-2012

Nikkam Suresh

IIT (ISM): Indian Institute of Technology

Gurdeep Singh

IIT (ISM): Indian Institute of Technology

\section{Research Article}

Keywords: Flocculation, Kinetics of settling, Turbidity removal, coal sedimentation, Washery water clarification, Polymeric flocculants

Posted Date: March 29th, 2021

DOI: https://doi.org/10.21203/rs.3.rs-285663/v1

License: (a) (1) This work is licensed under a Creative Commons Attribution 4.0 International License. Read Full License 


\section{Abstract}

Settling tests were conducted on the washery effluent using three types of flocculants namely cationic (Telfloc-3674F), anionic (Magna-1011) and non-ionic (Nalco-83370 + ). For the study purpose coal washery effluent (having pH of 8.72) was collected from a newly commissioned plant-thickener. Tests were conducted by varying the $\mathrm{pH}$ of the pulp at three levels of acidic (4.0), alkaline (11.0) and the natural $\mathrm{pH}$ (8.72) of the as collected effluent, besides the flocculent dosages varied at four levels $(2,4,6$ and $8 \mathrm{gpt})$ for each of the flocculants stated. The results of these tests, estimated in terms of initial settling rate and turbidity indicated that; among the three flocculants tested Telfloc-3674F and Magna-1011 gave best results as compared to Nalco-83370 + flocculent at a washery water $\mathrm{pH} 8.72$. The effect of molecular weight of the flocculants on settling of solids in effluent has been established in terms of the kinetics with a characteristic number for each of the type of flocculants used.

\section{Introduction}

With advancements that have taken place in the field of mining, proportion of fines generation in the ROM coal has gone up appreciably. This resulted in numerous environmental problems related to air-water pollutions. Further, Indian coals possess difficult-to-wash property which needs finer size reductions for improved liberation prior to washing. This has resulted in generation of excess fines in the coal being sent to washing circuits. Coal (hydrophobic) along with other mineral fines (hydrophilic) like shale, slate, clay and several other impurities are generated during stacking, handling, transportation, and dumpling at different points in CPP (Duong et al. 2000). Coal washing involves wet processes where coal gets mixed with water, and requires efficient dewatering and clarification techniques. Coal being hydrophobic in nature, at finer sizes the particles remain suspended in water and do not settle even after several days, particularly in tailing ponds. This pollutes the ground water and also deteriorates the agricultural land/crops surround it. Besides this the unclarified, when recirculated to coal washing plants, spoils the overall performance of the operating washery, because of accumulation of colloidal sized particles in excess. These problems are not limited only to the Indian coal washing circuits, but it is noticed globally in all the coal washeries (Moosavirad et al. 2010; Sabah and Erkan 2006; Gupta and Singh 1995; Sarioglu et al 2002).

To get-rid of all these problems, one alternative is to enhance the settling rate of particulate solids using flocculants (Khandal 1985). Polymer flocculants show higher efficiency and acceptability in wastewater/effluent treatments (Bolto and Gregory 2007; Lee et al. 2014; Teh et al. 2016; Dao et al. 2016) especially for removing suspended particulate matter that are accountable for high turbidity (Haiyang et al. 2017). Flocculants are high-molecular long chain water-soluble polymeric compounds that bind the surfaces of the dispersed particles physically and combine them to form agglomerates known as flocs that settle rapidly. The widely used flocculants are; the polyelectrolytes of anionic or cationic or non-ionic types having high molecular weight with different structures of macromolecules which intensify the solid-liquid separations in coal washing plants (Yakovchenko et al. 2019). Long-back Slater and Kitchener reported that the application of certain polymers as flocculants helped in promoting the settling rates of solids in industrial disperse systems (Slater and Kitchener 1966). 
Water clarification plays a major role in the overall economics of the coal preparation plants (CPP). As per the present environmental policies no effluent/slurry is allowed to be discharged outside the washery premises. Under these circumstances, water clarification using flocculants will help to abide by the guidelines set by MoEF, Gol, 2010, wherein the CPP are to operate the plants on a closed system watercirculation basis, and limit the fresh water consumption not exceed above $1.5 \mathrm{~m}^{3}$. Nowadays, the washeries are designed for closed-circuit system, where the water used in washing circuits to wash the raw coal is recycled and reused. Since this water detains appreciable percentage of colloidal size coal fines and clay particles, need to be clear-off dirt and contain only negligible amounts of suspended particles. Otherwise, huge volume of water would be required to process the coal. But, the removal of these colloidal fines (or water clarification) from the tailing slurry has posed number of challenges.

As a general norm, fines having size less than $0.50 \mathrm{~mm}$ are generally responsible for forming slurry in the washery (Ash and Rao 1972). Thus, an appropriate solid-liquid separation has become an essential part of a coal washing plant. In practice, the prevalent method adopted is sedimentation with aid of flocculants in thickeners, using polymeric flocculants. This method has two significant strictures that evaluate flocculation performance (Oruç et al. 2010).

i. The first is the low water-turbidity, since water recovered at the thickener overflow is recycled to the plant. The suspended colloidal particles in the recycled water should be at the lowest level, eliminating any negative implications to the process.

ii. The second is, settling rate of the flocculated particles, has a direct effect on thickener capacity as well as flocculent performance.

Thus, the challenge is dual; precise determination of various properties of the washery water effluent, this includes mineralogy of the gangue particles, physic-chemical properties such as $\mathrm{pH}$, conductivity, pulp density, TDS, alkalinity, hardness etc. besides electro-kinetic properties of the solid matter in washery effluents.

Achieving the lowest water turbidity level while maintaining high settling rate typically influenced and controlled by polymeric flocculent properties, its dosages and the $\mathrm{pH}$ value of the washery effluent. Moreover, the efficiency of the process is dependent on the use of accurate type of flocculants (i.e. anionic, cationic and non-ionic polymer) as well as the addition of their dosage (Sabah and Cengiz 2004; Pal et al. 2008).

On the other hand, water is becoming a scarce commodity, and several governmental slogans are heard every day to save water under the government's national policy. Still, the problem of water purification persists and supply of good quality water remains as a major problem. Thus, coal-water slurry handling has become an integral part of a coal beneficiation plant. This is because, the amount of fine-coal tailings generated annually is very high. To overcome the difficulties faced, the alternatives left are:

i. Development of efficient solid-liquid separation systems,

ii. Selection and addition of the correct flocculent. 
iii. Understanding of the interaction between the flocculent and the slurry is vital in achieving optimum condition.

In view of the above, in this study the influence of flocculent types, their dosage effects and effect of pH of the pulp on the settling of fine coal fines has been attempted after the physico-chemical and mineralogical characteristics of an effluent collected from a thickener of an operating plant (Dahibari, India).

\section{Materials Used And Their Characterization}

2.1 Sample Collection and plant details: Coal washery effluent form a tailing thickener of Dahibari coal washing plant operating under Bharat Coking Coal Limited, Dhanbad, was collected from the feed-well pipe of the thickener. Collection of the effluent sample was made in large capacity plastic containers with their lids fitted air-tight and stored intact as per guidelines given by American Public Health Association (APHA 2012). Among the several containers, one of the container was selected, the slurry was filtered and dried. The solids obtained thereof were analysed for the characterisation studies in detail.

About Dahibari coal washing plant: Dahibari washery was designed for washing of high-ash Indian coals, that are recently classified and categorised as washery grade IV (with 28 to $35 \%$ ash) and washery grade V (with 35 to $42 \%$ ash). This is a standalone-type coal washery commissioned in the year 2018 with a treatment capacity of 1.6 MTPA of coal that produces small quantity of washed coking coal (of $19 \%$ ash) and the power coal (middling) as its final products. Both washed coal (of 19\% ash) and the middling (with $33.5 \pm 0.50 \%$ ash to captive power plants) are sent to SAIL steel plants. Since the washery was designed to receive coals from different collieries, it falls under the category as NLW (Non-linked washery). Hence the feed ash of raw coal to the washery varies very widely ranging from $28 \%$ to $40 \%$. Raw coal crushed to 30 $\mathrm{mm}$ is washed with the help of heavy media cyclones and thickeners installed for the collections of comparatively large-sized fraction of fines. The supernatant water of the thickener impounded is recirculated to the plant while the sludge of the thickener is store in tailing ponds. The satellite location map (latitude $=23^{\circ} 72^{\prime} 91.4^{\prime \prime} \mathrm{N}$ and longitude $=86^{\circ} 77^{\prime} 92.0^{\prime \prime} \mathrm{E}$ ) of Dahibari is given in Fig. 1 .

2.2 Characterization of Sample: Characterization studies on the collected effluent sample was carried out to know the physico-chemical parameters of slurry viz. $\mathrm{pH}$, conductivity and TDS were measured onsite while the other parameters in the laboratory. The collected effluent showed a natural pH of 8.72 and high turbidity value of 1370 NTU, which may be because of presence of colloidal fines necessitating addition of flocculent for improved clarification. All the physic-chemical properties of the effluent are presented in Table 1. For other characterization studies of coal in effluent, a small amount of slurry was dried $a 0^{\circ} \mathrm{C}$ and the results are presented in Table 2. Details of the major instruments used for characterization studies are mentioned in Table 3.

2.3 Water and Flocculants used: The washery-water slurry of natural $\mathrm{pH} 8.72$ was used to study settling test. To study the effect of $\mathrm{pH}$ of pulp (4.0 and 11.0), the same washery-water was induced by addition of required amount of $1 \mathrm{~N}$ Hydrochloric acid (HCL) supplied by M/s RFCL Ltd., New Delhi, India and 1N Sodium Hydroxide $(\mathrm{NaOH})$ supplied by Merck Specialities Pvt. Ltd., Mumbai, India. For experimental 
work three types of flocculants were selected namely viz., Cationic flocculent - Telfloc-3674F (TF), Anionic flocculent - Magna-1011(MF) and Non-ionic - Nalco-83370+(NF). Settling tests were performed by varying each of the above stated flocculants at 3 levels. TF is a medium molecular weight cationic polyacrylamide was supplied by M/s lon Exchange India Ltd., Patancheru, India. MF is a high molecular weight anionic polyacrylamide supplied by M/s BASF, India. Whereas, NF is a non-ionic polymer supplied by $\mathrm{M} / \mathrm{s}$ Nalco, India as presented in Table 4. For each test desired amount of freshly prepared flocculent was used after diluting it to $0.1 \% \mathrm{w} / \mathrm{w}$ homogeneous stock solution to study the dosage variations. Fresh flocculent solutions were prepared at an interval two days to improve the precession of results.

\section{Flocculation Tests And Experimental Studies}

A total of 36 Settling tests were performed using three different flocculants. For each type of flocculent, its dosages were varied at four levels and for each dosage of the flocculent, three $\mathrm{pH}$ levels were studied. In all these tests a fixed pulp solids concentration of $3.0 \% \mathrm{w} / \mathrm{w}$ was kept constant (as per prevailing practice at the plant). All these tests were performed at the room temperature varying between $25-30^{\circ} \mathrm{C}$. The details of the test conducted along with the levels of the variables studied are summarised in Table 5. Each of these settling test were performed in a $1000 \mathrm{~cm}^{3}$ graduated measuring cylinder as per ASTM (ASTM 2008) standard jar-test method. For homogeneous mixing of slurry, a constant mixing time of $3 \mathrm{~min}$ was applied to the collected grab sample prior to each tests. The desired amount of flocculent was added to the slurry, followed by manual stirring for $30 \mathrm{sec}$. The change in the interface heights as a function of time was recorded for plotting of the settling curves. The interface heights of slurry for the chosen time intervals of 0 , $15,30,45,90,120,180,300,600$ seconds were noted. Using this data, settling rates were established graphically from the slope of the straight line of settling curve obtained as per standard procedure (Fig.6c). After $600 \mathrm{sec}$ of settling time, an aliquot of the supernatant was taken for the turbidity measurements using turbidimeter.

\section{Discussion On The Results Of Characterization Tests Conducted}

The following characterization studies were carried out on the high-ash Dahibari effluent fines:

a. Granulometric analyses of coal washery effluent: The particle size distribution patterns expressed in both differential and cumulative forms (by volume percentages) washery effluent are shown in Figs. 2a and $2 \mathrm{~b}$ respectively indicating about $80 \%$ of the particles are below $60 \mu \mathrm{m}$ in the effluent (Fig. $2 \mathrm{~b}$ ).

b. Zeta potential studies: The zeta potential of the suspension plays an important role in flocculation. It is a measure of surface charge acquired on the particles in washery effluent. The results of Zeta potential of Dahibari washery effluent as a function of $\mathrm{pH}$ is shown in Fig. 3 . The zeta potential value of the particles at natural $\mathrm{pH}$ of 8.72 was $10.3 \mathrm{mV}$ exhibiting positive surface charge at all pH values except at $\mathrm{pH}$ 12. The addition of $\mathrm{OH}^{-}$ions (from $\mathrm{NaOH}$ ) is accountable to revert the positive surface charge into negative at alkaline $\mathrm{pH} 12$ of effluent. The positive surface charge may be due the presence of aluminosilicates along with sodium and potassium. However, in the presence of flocculants at a $\mathrm{pH}$ of 8 the value of the zeta potential gets increased to $-70.1 \mathrm{mV},-69.1 \mathrm{mV}$ and $-52.8 \mathrm{mV}$ for TF, MF and NF 
flocculants respectively. According to the ASTM D-4187 Standard Test Method, if the zeta potential of colloids (colloidal particles) in water or waste slurry is above $-60 \mathrm{mV}$, the stability of the system is classified as 'perfect' (Sabah and Erkan 2006). Since, the present case zeta potential for the coal slurry was observed to be $10.3 \mathrm{mV}$ at the $\mathrm{pH} 8$, this was classified and considered as highly stable condition, suggesting the possibility of increase in settling characteristics through flocculation.

c. XRD analysis of coal: The adsorption of a flocculent depends on the mineralogical assemblages of the suspended particulate matter, in addition to the prevailing aqueous environment i.e., in the present case the quality of effluent collected from the washery. Therefore, it was necessary to identify the gangue mineral components present in the feed coal. The XRD pattern of the washery effluent coal is represented in Fig. 4, which indicates the presence of quartz, kaolinite and muscovite as the gangue minerals present in the order of increasing intensity of XRD.

d. TG-DTA analysis of feed coal: To confirm the results of proximate analysis of coal TG-DTA test were conducted at a heating rate of $10 \mathrm{~K} / \mathrm{min}$ in oxygen atmosphere on the coal washery effluent. The TGDTA peaks shown in Fig. 5 depicts a drastic weight loss over $300-600^{\circ} \mathrm{C}$ temperature range in the TGA curve is due to decomposition of carbon, volatile matter and moisture of the coal. Similar observations were also made by Sabah et al. (Sabah et al. 2004).

\section{Results And Discussion}

To identifying a most suitable type of flocculent for improved clarification of coal washery effluent, the results of all the jar settling tests conducted have been analyzed in terms of (i) initial settling rates and (ii) the turbidity of the aliquot supernatant liquid. These two responses were determined as stated below:

Estimation of Initial Settling rate: This was determined graphically (as per the standard practice) by plotting the height of the slurry-water interface measured as function of time. The value of the slope of the settling curve estimated graphically in the near straight-line region of initial settling periods is considered as the 'initial settling rate'. This is shown in Fig.6c as a typical example (for a test done at 4gpt of dosage at a pH of 8.72 of the flocculent TF). Together with the settling curve (Fig.6c), a comparison of settling data with the zones noticed in thickeners corresponding to the interfaced seen in a jar test is made in Figs. 6 ( $a$ and $b$ ).

Suspension Turbidity: Turbidity of the aliquot drawn from the supernatant liquids at the end of 600 seconds were measured by Turbidimeter. These results were used in conjunction with the initial turbidity of the washery effluent to measure the 'Turbidity Removal Efficiency' given as (Osborne 1978; Ozkan and Yekeler 2004; Ozkan et al. 2016):

$$
\text { Turbidity removal efficiency, } \%=\left[1-\frac{\mathrm{T}_{f}}{T_{o}}\right] * 100 \quad \text { Eq. (1) }
$$

Where, $T_{o}$ - is the initial turbidity (Nephelometric turbidity unit, NTU) of the washery effluent, $T_{f}$ - is the final turbidity of the supernatant liquid obtained after flocculation at the end $600 \mathrm{sec}$.

\subsection{Effect of flocculent type and its dosages on initial settling rates}

In flocculation, the molecular weight of a flocculent affects the performance as it controls the inter-particle bridging mechanism, and so the clarification. Literature cited on this aspect revealed that (Reuter and Hartan 1986; Duong et al. 2000; Negro et al. 2005; Sabah and Erkan 2006; Vajihinejad et al. 2019) higher molecular weight results in 
improved bridging mechanism, despite the evidences where, increase in molecular weights beyond certain limit, results in deleterious effects. This in fact may be because; very high molecular weight flocculants generally are more viscous and do not mix properly or get distributed throughout the slurry. This affects the adsorption, which has to be very rapid. In view of this in the present study, three different molecular weight flocculants (of high; MF, medium; TF and low; NF) were selected as specified in Table-4.

Figs.7 (a to c) are plotted to analyse and compare the influence of the three flocculent types (TF, MF and NF) by considering the initial settling rates of the flocs at varied flocculent dosages (varied from 2gpt to 8gpt), for the tests conducted at a constant level of $\mathrm{pH}$ in each of these figure. The maximum initial settling rate observed is for the flocculants TF and MF with the initial settling rate values of 0.4178 and $0.3333 \mathrm{~cm} / \mathrm{sec}$ respectively. whereas, with low-molecular weight flocculent NF the highest initial settling rate noticed is $0.2960 \mathrm{~cm} / \mathrm{sec}$ when analysed at a fixed dosage of $8 \mathrm{gpt}$ at a natural $\mathrm{pH}$ of 8.72 . This established clearly the influence of molecular weight and the iconicity of the flocculants studied (Table 4).

Further, the effect of dosage of the flocculants added is also illustrated in these figures, where; an increase in the settling rate of coal (together with mineral impurities) also increases gradually and touches a highest value (Angle et al. 1997; Somasundaran and Das 1998; Sabah and Erkan 2006) with increased flocculent dosage. The variations noticed in the settling rates are significant only after 6gpt of flocculent addition, for all the three types of flocculants tested. However the reason for low settling rates at lower dosages for a given $\mathrm{pH}$ may be due to the inadequate concentration of polymer for adsorption onto the surface of the particles (Sabah and Aciksoz 2012; Sabah et al. 2003).

\subsection{Influence of $\mathrm{pH}$ of effluent on settling rate}

The $\mathrm{pH}$ value of an effluent plays a significant role on adsorption of a polymer onto the surface of particle and sizegrowth of flocs in slurry (Stutzman and Siffert 1977; Somasundaran and Das 1998; Yu and Somasundaran 1996; Pefferkorn 1999; Rattanakawin and Hogg 2001; Sabah et al. 2003). Figs. 7 (a to c) are plotted to study the effect $\mathrm{pH}$ variations clearly depicts that at natural $\mathrm{pH}(\mathrm{pH}=8.72)$, initial settling rates observed are of high values than that of acidic $(\mathrm{pH}=4.0)$ and alkaline $(\mathrm{pH}=11.0) \mathrm{pH}$ levels of the effluent. This implies that, in acidic and alkaline $\mathrm{pH}$ levels, excess of $\mathrm{H}^{+}$and $\mathrm{OH}^{-}$ions occupy the surface of oppositely charged mineral impurities associated with coal fines and also resist the extension of long-polymer chains in slurry, despite of its high dosages which negatively affects flocculation process \& lowers down the rate of settling (Moyakhe et al. 2017).

Incidentally, the cationic polymer (TF) has positive charge patch of quaternary ammonium, sulphonium or phosphonium ions (Vajihinejad et al. 2019) that adsorb through long chain polymer bridging onto the positive charge surface of particles present in effluent. Simultaneously, the negative charge patch of carboxylic group on the anionic polymer (MF) gets adsorbed on the positively charged particles present in the washery effluent through charge neutralization. While, the non-ionic polymer (NF) gets adsorbed through hydrogen bonding or hydrophobic interactions (Littlefair and Lowe 1986; Sabah et al. 2003) during floc formation of the particles present in Dahibari washery effluent. This implies involvement of different mechanisms at different $\mathrm{pH}$ ranges in clarification of Dahibari washery effluent. Thus resulting retarded settling rates in acidic and alkaline $\mathrm{pH}$ conditions of the effluent. Therefore a natural $\mathrm{pH} 8.72$ is found to be effective for all types of flocculants used in this study to enhance the settling rates.

\subsection{Effect of turbidity analogous to settling rate}

Since the Dahibari coal washery effluent consisted of kaolinite (clay) and muscovite minerals. Both being flaky/lath shaped particles, do not settle easily and remain suspended, leading to high turbidity of the aliquot. Turbidity of

Page $7 / 18$ 
Dahibari washery gave a value of 1370 NTU at natural pH of 8.72 imparting black colour to the effluent (Table 1). Figures 8 (a to c) shows a maximum turbidity removal of 99.19\% (11.1 NTU), 99.28 (9.8 NTU) and 93.20 (93.1 NTU) for TF, MF and NF respectively at 8gpt of floc dosage and natural pH of 8.72. This analogous to the initial settling rates mentioned in section 5.1. A highest turbidity reduction of 9.8 NTU was noticed with MF because of oppositely charged physical bonding between the particles in effluent and the anionic surface charge of flocculent. Besides this, the variations noticed in turbidity results is due to high molecular weight of polymers leading to formation of large sized but less compact flocs, while the low molecular weight polymers show a reverse phenomenon resulting in formation of small and more compact flocs (Gregory 1989; Hogg 2000; Tao et al. 2000; Sabah et al. 2003).

In general, at slow initial settling rates, the colloidal particles in effluent get more time to interact with polymer and also more inter-particle collisions to form strong flocs resulting in more clarity of supernatant. But in the present case, for the cationic and anionic flocculants, even with higher initial settling rates the turbidity removal efficiencies noticed are high.

However figures 8 ( $\mathrm{d}$ to $\mathrm{f}$ ) and 8 ( $\mathrm{g}$ to i) clearly represent that even with reduced initial settling rate values (noticed at acidic and alkaline $\mathrm{pH}$ levels) the turbidity removal efficiencies did not improve. This observations is noticed at all the dosage levels of the flocculants. In other words, even with increased flocculent dosage, the turbidity removal efficiency do not meet the high values observed with that of natural $\mathrm{pH}$ of 8.72 . This is mainly because of the presence of excess of $\mathrm{H}^{+}$and $\mathrm{OH}^{-}$ions that hinder the polymer adsorption activity onto the surface of particles present in Dahibari washery effluent. It can be concluded from figure 8 that high supernatant clarity does correspond to high settling rate.

\subsection{Settling kinetics}

The effect of flocculants (TF, MF and NF) on clarification of Dahibari effluent has been assessed for the date of natural pH (8.72) using a standard second-order kinetic model given as (Raj 2001):

\section{Second Order Rate, $\mathrm{K}_{2}=\left[\left(\frac{1}{(a+t)}\right) *\left(\frac{x}{(a-x)}\right)\right]$}

Where ' $a$ '- is the initial height of effluent in a jar test, and ' $x$ '- is the final interface height of effluent after addition of flocculent measured at time ' $\mathrm{t}$ '.

From Eq.2, the efficiency of flocculation can be estimated by plotting the second order rate constant $\mathrm{K}_{2}\left(\mathrm{~cm}^{-1} \mathrm{sec}^{-1}\right)$ against time-'t'. Gregory (Gregory 2013) described it as second-order rate equation based on collision theory for flocculation.

The Plots shown in Figures 9 (a to c) represent the settling curves at varied flocculent dosages for three different flocculants (TF, MF and NF) obtained at the natural pH of Dahibari washery effluent $(\mathrm{pH}=8.72$ ). Figures 10 ( a to c) represent their corresponding second order kinetic plots. It can noticed from the settling curves of TF and MF that, all the curves show almost a linear variation with time upto 90sec, and then deviate with prolonged settling time, finally to remain constant after $120 \mathrm{sec}$ of settling time. Whereas, the low molecular weight flocculent NF although shows the linearity in settling upto 90sec, but an exponential variation in settling is noticed till 240 sec of settling time which eventually tends to an asymptotic value i.e. after 240 sec of time. 
In Figures 10 (a to $\mathrm{c}$ ), the discrete settling rate constants ( $\Delta \mathrm{h} / \Delta \mathrm{t}$ ) estimated at a different settling durations are plotted against time. This was felt necessary because, most of the settling curves overlapped each other indicating almost similar settling pattern in Figs.9 (a to c). However, the plots shown in Figs. 10 (a to c) clearly depict a distinguishable variations in their linearity following the second order kinetic settling rate for all the three types of flocculants tested. It is interesting to note that, from the slope of these plots, the plotted lines converge and overlap each other with decreased molecular weight of flocculants. This implies the dosage variations made with the low molecular weight flocculent (NF) is marginal and insignificant.

\section{Variation in rate constant with flocculent dosage:}

Further, observing to the slopes of the straight lines shown in Figs. 10 (a to c) with a changed flocculent dosages, their slopes were found to increase with the addition of flocculent quantity (gpt.). Higher flocculent dosages gave higher slope values and vice-versa. The variation in slopes noticed is also dependent on the type of flocculent and its molecular weight. Now to understand the effect of flocculent dosage on overall settling rate, Figure 11 has been plotted by taking dosage in gpt (on abscissa) against the value of $\mathrm{K}_{2}$ (in ordinate) for a given flocculent. In this case also a linear variation of $\mathrm{K}_{2}$ with the flocculent dosage is observed. The values of the slopes of the lines shown in this plots can be taken as the 'characteristic number' which is dependent of the type and molecular weight of the flocculent when tested at a pH of 8.72 for the Dahibari washery effluent. In other words, the values of these characteristic numbers given as 1.9945 for TF (cationic), 1.229 for MF (anionic) and 0.249 for NF (non-ionic) flocculent types.

\subsection{Characterization of effluent coal and flocs}

\subsubsection{Particle size analysis of effluent coal and flocs}

The particle size analysis performed by laser beam particle size-analyzer on the as obtained effluent sample of Dahibari washery and also of the flocculated flocs obtained with $8 \mathrm{gpt}$ of dosage at natural pH of 8.72 using three different types of flocculants (anionic, cationic and non-ionic) are shown in Figs. 12 (a and b) for comparison purpose. Figure 12a represents differential plots in percent volume. Looking at the peak areas of the plots, the peaks obtained with TF \& MF overlap on to each other indicating similar performances. Fig. 12b shows that the values for $\mathrm{D}_{10}, \mathrm{D}_{50}$ and $\mathrm{D}_{90}$ percent passing sizes of flocs and also of the feed effluent collected from Dahibari washery. The sizes obtained with TF and MF flocs are bigger and overlap, this supported their high initial settling rate study mentioned in section 5.1.The particle size distribution of the washery effluent and other minerals particles was observed in the range of 4.4 to $142 \mu \mathrm{m}$, this size range of particles in effluent get increased to 52 to $327 \mu \mathrm{m}$ for $\mathrm{TF}, 45$ to $300 \mu \mathrm{m}$ for MF and 19.7 to $169 \mu \mathrm{m}$ for NF which indicate formation of flocs after flocculation. These observations are in accordance with that of Gungoren et al (Gungoren et al. 2017).

\subsubsection{FTIR analysis of effluent coal and flocs}

Figure 13 is the result of FTIR analysis study of the washery effluent and flocculated flocs. The peaks of these plots show only the presence of inorganic Si-O bending vibrations in the region of $1100-1000 \mathrm{~cm}^{-1}$ (Zhichao et al. 2017) subsequently extended its symmetric stretching vibration peaks of Si-O appeared at $802 \mathrm{~cm}^{-1}$ which shows its bending vibration at $470 \mathrm{~cm}^{-1}$. The peaks in FTIR spectra of coal between 1100 and $400 \mathrm{~cm}^{-1}$ can be assigned to clay minerals (Kaolinite) and quartz, (Saikia et al. 2007). The areas of these spectrum showed noticeable deep stretched peaks after flocculation with polymers (TF, MF and NF) in the present study. The transmittance 
percentages of Dahibari effluent coal flocs gets shifted upward above the effluent transmittance values after flocculation indicating adsorption of polymers to the inorganic (clay, quartz) associated with the coal surface.

\section{Conclusion}

- Characterization studies conducted on Dahibari washery effluent by various methods indicated effluent is of highly heterogeneous nature witness from its physico-chemical properties.

- The collected effluent showed presence of colloidal fines with D80 percent passing size=60 $\mu \mathrm{m}$ which results in high turbidity value of 1370 NTU. Thus hindered the natural settling of coal particles in thickener when observed at a natural $\mathrm{pH}$ of 8.72 of effluent without the addition flocculent. This lead to conclude that addition of flocculent as a necessary step.

- The results of the flocculation tests indicated that, all the three flocculants tests gave satisfactory results for clarification of the water of Dahibari washery effluent. However, among the three flocculants tested, the cationic (TF) and anionic (MF) polymer flocculants gave better results in terms of initial settling rates and the measured turbidity values.

- Second order kinetic rate constants estimated elaborate the results of effective clarification occurred between polymer flocculants and the suspended particles of Dahibari effluent.

- The order of effectiveness of polymer flocculants is TF $>$ MF $>$ NF. The overall results of the study indicated that, the TF and MF are most suitable for clarification of Dahibari coal washery effluent to reutilize the treated water in coal washing circuits and to reduce the fresh water consumption for coal washing process.

\section{Declarations}

\section{Ethical Approval}

The authors of this paper hereby confirm that all the procedures described, tests performed, studies conducted, data presented and the interpretations made thereof on data are in accordance with ethical standards of the institution. However the site map of the Dahibari washery presented and the thickener diagram (Fig. 6a) from the website for which the reference has been cited.

\section{Consent to Participate}

Not Applicable.

\section{Consent to Publish}

All the authors of this paper hereby give their consent publish the contents of the paper after its peer review. Authors have no objection in publishing the data or analytical contents of the paper in the journal.

\section{Availability of data and materials}


The material was obtained officially from the Dahibari coal washery, BCCL, Dhanbad after taking the consent from the washery management. The data presented are results of the tests conducted in the laboratory using a $1000 \mathrm{ml}$ jar test as per standard practice.

\section{Competing interest}

The authors hereby declare that there is no competing interests.

\section{Funding}

This research did not receive any specific grant from any of the funding agencies.

\section{Authors contribution}

Ms Sarika Pimpalkar, the first author of this paper has carried out all the experiments in the laboratory under the supervision of Prof Nikkam Suresh and Prof Gurdeep Singh. The supervisors have helped in designing of the experiments, analysis of the data and also in correcting the draft copy of this research paper.

\section{Acknowledgements}

The authors wish to express their appreciation towards the necessary facility and support provided by the Department of Fuel, Mineral and Metallurgical Engineering and Department of Environmental Science and Engineering, Indian Institute of Technology (Indian School of Mines), Dhanbad, for execution this research work. The authors also express their gratitude to Dahibari Washery Management, BCCL for providing the washery effluent for the study.

\section{References}

American Public Health Association (2012) Standard methods for the examination of water and wastewater (22nd ed). Washington, D.C.

American Society for Testing Materials (2008) Standard practice for coagulation-flocculation jar test of water (D2035-08).

Angle CW, Smith-Palmer T, Wentzell BR (1997) The effects of cationic polymers on flocculation of a coal thickener feed in washery water as a function of pH. J Appl Polym Sci 64(4):783-789.

Ash PN, Rao RRS (1972) Studies on coal preparation in India. Dhanbad: Central Fuel Research Institute.

Bolto B, Gregory J (2007) Organic polyelectrolytes in water treatment. Water Res 41:2301-2324. doi.org/10.1016/j.watres.2007.03.012

Dao VH, Cameron NR, Saito K (2016) Synthesis, properties and performance of organic polymers employed in flocculation applications. Polym Chem 7:11-25. doi.org/10.1039/c5py01572c 
Das B, Prakash S, Biswal SK, Reddy PSR (2006) Settling characteristics of coal washery tailings using synthetic polyelectrolytes with fine magnetite. J S Afr I Min Metall 106:707-712.

Duong C, Choung J, Xu Z, Szymanski J (2000) A novel process for recovering clean coal and water from coal tailings. Miner Eng 13(2):173-181.

Gregory J (1989) Fundamental of Flocculation. Crit Rev Environ control 19(3):225-230.

Gregory J (2013) Flocculation Fundamentals. Encyclopedia of Colloid and Interface Science, ed. T. Tadros, Springer-Verlag Berlin Heidelberg 459-624. doi:10.1007/978-3-642-20665-8

Gungoren C, Baktarhan Y, Kursun I, Ozkan SG, Ozdemir O (2017) Determination of floc size and strength of fine coal tailings using laser diffraction technique. Int Symposium Mining Environ (ISME conference), 27-29 September 2017, 609-16 Bodrum/Turkey.

Gupta RK, Singh G (1995) Water pollution profile of coal washeries. Pollut Res 14(2):203-213.

Haiyang X, Jing L, Renjie F, Cheng R, Wang S, Zhang J (2017) Flocculation of coal washing wastewater using polysaccharide produced by Paenibacillus mucilaginosus WL412. Environ Sci Pollut Res (2017) 24:28132-28141. doi 10.1007/s11356-017-0340-4

Hogg R (2000) Flocculation and dewatering. Int J Miner Process 58:223-236.

IS 2490-1 (1981) Tolerance limits for industrial effluent. New Delhi: Bureau of India Standards (BIS).

Kapse G, Patoliya P, Samadder SR (2017) Characterisation of coal washery effluent and optimization of coagulation behaviour of Moringa oleifera seed as a coagulant. Environ Monit Assess 189:133. doi 10.1007/s10661-017-5844-3.

Khandal RK (1985) Effect of coagulants on flocculation of coal fines by polymer flocculants. Proc. Indian natn Sci Acad 51:863-871.

Lee CS, Robinson J, Chong MF (2014) A review on application of flocculants in wastewater treatment. Process Saf Environ Prot 92:489-508. doi.org/10.1016/j.psep.2014.04.010

Littlefair MJ, Lowe NRS (1986) On the selective flocculation of coal using polystyrene latex. Int J Miner Process 17:187-203.

Moosavirad SM, Shankara M, Janardhana MR (2010) Geochemistry of coal washery effluents in Zarand region, Kerman province, South-east of Iran. Asian J Environ Sci 5(2):144-148.

Moyakhe DM, Campbell QP, Fosso-Kankeu E (2017) The effect of flocculant type on settling properties of fine coal tailings. 9th Int'I Conference on Advances in Science, Engineering, Technology \& Waste Management (ASETWM-17) Nov. 27-28, 2017 Parys, South Africa. 
Negro C, Blanco A, Fuente E, Sanchez LM (2005) Influence of flocculant molecular weight and anionic charge on flocculation behaviour and on the manufacture of fibre cement composites by the Hatschek process. Cement and Concrete Research 35(11):2095-2103. DOI: 10.1016/j.cemconres.2005.03.004

Oruç F, Ozgen S, Sabah E (2010) An enhanced-gravity method to recover ultra-fine coal from tailings: Falcon concentrator. Fuel 89(9):2433-2437.

Osborne DG (1978) Recovery of slimes by a combination of selective flocculation and flotation. Miner Process Extr Metall 87:189-193.

Ozkan A, Oner B, Onen V, Duzyol S (2016) Flocculation of coal suspension with mono/dual polymer systems and contribution of $\mathrm{Ca}(\mathrm{II}) / \mathrm{Mg}(\mathrm{II})$ ions. Sep Sci Technol 51(1):106-114.

Ozkan A, Yekeler M (2004) Coagulation and flocculation characteristics of celestite with different inorganic salts and polymers. Chem Eng Process 43:873- 879.

Pal S, Sen G, Karmakar NC, Mal D, Singh RP (2008) High performance flocculating agents based on cationic polysaccharides in relation to coal fine suspension. Carbohydr Polym 74:590-596.

Pefferkorn E (1999) Polyacrylamide at solid/liquid interfaces. J Colloid Interface Sci 216:197-220.

Raj G (2001) Advanced Physical Chemistry 677-680 25th ed. Meerut, UP/India Goel Publishing House.

Rattanakawin C, Hogg R (2001) Aggregate size distributions in flocculation. Colloid Surf A- Physicochem Eng Asp 177:87-98.

Reuter JM, Hartan HG (1986) Structure and reaction kinetics of polyelectrolytes and their use in solid-liquidprocessing. Aufbereitungs-Technik 11:598-607.

Sabah E, Cengiz I (2004) An evaluation procedure for flocculation of coal preparation plant tailings. Water Res 38:1542-1549.

Sabah E, Erkan ZE (2006) Interaction mechanism of flocculants with coal waste slurry. Fuel 85:350-359.

Sabah E, Ersoy B, Cengiz I (2003) Flocculation mechanism of coal preparation plant tailings with various type polymers. Proceedings of the X. Balkan Mineral Processing Congress 292-299, 15-20 June 2003, VarnaBulgaria.

Saikia BK, Boruah RK, Gogoi PK (2007) FT-IR and XRD analysis of coal from Makum coalfield of Assam. J Earth Syst Sci 116(6):575-579.

Sarioglu M, Cebeci Y, Beyazit N (2002) Investigation of the effects of some operating parameters using anionic and cationic flocculants for removing solid material in the lignite. Asian J Chem 14(1):388-394.

Slater RW, Kitchener JA (1966) Characterization of flocculation of mineral suspensions by polymers. J Discussions Faraday Soc 42:267-75. 
Somasundaran P, Das KK (1998) Flocculation and selective flocculation - an overview. In Proceedings of 7th International Mineral Processing Symposium (Innovation in mineral and coal processing), ed. AS Onal, G Celik, MS Istanbul 81-91 Turkey, Balkema.

Tao D, Groppo JG, Parekh BK (2000) Enhanced ultrafine coal dewatering using flocculation filtration processes. Miner Eng 2:163-171.

Teh CY, Budiman PM, Shak KPY, Wu TY (2016) Recent advancement of coagulation-flocculation and its application in wastewater treatment. Ind Eng Chem Res 55:4363-4389. doi.org/10.1021/acs.iecr.5b04703

Vajihinejad V, Sarang P, Gumfekar, Bazoubandi B, Najafabadi ZR, Soares JBP (2019) Water soluble polymer flocculants: Synthesis, Characterization and performance assessment. Macromol Mater Eng 304(2):1-43.

Wakeman RJ.Thickners. doi: 10.1615/AtoZ.t.thickeners as appeared in website: https:// thermopedia.com/content/1198/

Yakovchenko MA, Pinchuk LG, Kolosova MM, Filipovich LA, Masaev VY (2019) Intensification of wastewater treatment processes during coal enrichment using modified polyacrylamide flocculants. IOP Conf Ser: Earth Environ Sci 224:1-6. 012051 IOP Publishing. doi:10.1088/1755-1315/224/1/012051

Yu X, Somasundaran P (1996) Role of polymer conformation in interparticle-bridging dominated flocculation. J Colloids Interface Sci 177:283-287.

Zhichao Y, Wang W, Shengyu L (2017) Flocculation of coal waste slurry using bioflocculant produced by Azotobacter chroococcum. Energy Fuels 31(2):1460-1467.

\section{Tables}

Table 1: Physico-chemical characterization of Dahibari washery effluent sample 


\begin{tabular}{|c|c|c|}
\hline Parameter & Dahibari washery effluent & Permissible Discharge Limit IS:2490 (1981) \\
\hline Colour & Black & Colourless \\
\hline $\mathrm{pH}$ & 8.72 & $5.5-9.0$ \\
\hline Temperature, ${ }^{\circ} \mathrm{C}$ & 29.4 & $<40$ \\
\hline Conductivity, $\mu \mathrm{S} / \mathrm{cm}$ & 386 & - \\
\hline Turbidity, NTU & 1370 & - \\
\hline $\mathrm{COD}, \mathrm{mg} / \mathrm{L}$ & 300 & $250 \mathrm{mg} / \mathrm{L}$ \\
\hline Oil \& Grease, mg/L & 5.2 & $10.0 \mathrm{mg} / \mathrm{L}$ \\
\hline Total Hardness as mg/L $(\mathrm{Ca}+\mathrm{Mg}) \mathrm{CO}_{3}$ & 310 & - \\
\hline Calcium Hardness as mg/L $\mathrm{CaCO}_{3}$ & 306 & - \\
\hline Total Alkalinity as mg/L $\mathrm{CaCO}_{3}$ & 340 & - \\
\hline Total solid, mg/L & 7521 & - \\
\hline Total suspended solids, mg/L & 7120 & \\
\hline Total dissolve solids, mg/L & 401 & $2100 \mathrm{mg} / \mathrm{L}$ \\
\hline Chloride as mg/L NaCl & 450 & $1000 \mathrm{mg} / \mathrm{L}$ \\
\hline Fluoride, mg/L & 1.15 & - \\
\hline Sulphate as mg/L & 144 & $1000 \mathrm{mg} / \mathrm{L}$ \\
\hline Nitrate as mg/L & 2.76 & - \\
\hline $\operatorname{Iron}(\mathrm{Fe}), \mathrm{mg} / \mathrm{L}$ & 1.7 & - \\
\hline Aluminium (Al), mg/L & 0.2 & - \\
\hline Copper (Cu), mg/L & 0.1 & $3 \mathrm{mg} / \mathrm{L}$ \\
\hline Lead (Pb), mg/L & $\mathrm{BDL}$ & $0.1 \mathrm{mg} / \mathrm{L}$ \\
\hline Zinc (Zn), mg/L & 0.8 & $15 \mathrm{mg} / \mathrm{L}$ \\
\hline Cadmium (Cd), mg/L & $\overline{B D L}$ & $2 \mathrm{mg} / \mathrm{L}$ \\
\hline Arsenic (As), mg/L & $\mathrm{BDL}$ & $0.2 \mathrm{mg} / \mathrm{L}$ \\
\hline Chromium & $\mathrm{BDL}$ & $2 \mathrm{mg} / \mathrm{L}$ \\
\hline
\end{tabular}

BDL - Below Detection Limit i.e. -0.001 mg/L

Table 2: Characterization of Dahibari effluent coal 


\begin{tabular}{|c|c|c|}
\hline Properties & Unit & Values \\
\hline \multicolumn{3}{|c|}{ Proximate Analysis (Air dried basis) } \\
\hline Total Ash content, & $\%$ & 44.96 \\
\hline Volatile matter & $\%$ & 17.38 \\
\hline Moisture & $\%$ & 1.91 \\
\hline Fixed carbon & $\%$ & 35.75 \\
\hline \multicolumn{3}{|c|}{ Ultimate Analysis (Air dried basis) } \\
\hline Carbon & $\%$ & 33.26 \\
\hline Hydrogen & $\%$ & 7.56 \\
\hline Nirogen & $\%$ & 13.90 \\
\hline Sulphur & $\%$ & 0.036 \\
\hline Oxygen & $\%$ & 0.28 \\
\hline \multicolumn{3}{|c|}{ Other properties } \\
\hline $\mathrm{GCV}_{(\mathrm{EB})}^{\#}$ & $\mathrm{Kcal} / \mathrm{kg}$ & 3967.2 \\
\hline Specific Gravity & $\mathrm{kg} / \mathrm{m}^{3}$ & 1568.0 \\
\hline LTGK Grade & - & G12 \\
\hline Loss of Ignition (LOI), & $\%$ & 55.04 \\
\hline Particle size (D80p), & $\mu \mathrm{m}$ & 60 \\
\hline $\begin{array}{l}\text { Pulp density (solid concentration) } \\
\text { (as received basis) }\end{array}$ & $\% \mathrm{w} / \mathrm{w}$ & 3.0 \\
\hline Major gangue mineral & \multicolumn{2}{|c|}{ Kaolinite, quartz, muscovite } \\
\hline
\end{tabular}

\# Goss Calorific Value estimated under equilibrated condition (at Temp $=40^{\circ} \mathrm{C}$ and $\mathrm{RH}=60 \%$ )

Table 3: Major Equipment used for characterization 


\begin{tabular}{|c|c|c|c|c|c|c|}
\hline Sl.No. & $\begin{array}{l}\text { Name of } \\
\text { Equipment }\end{array}$ & Make & Model No. & $\begin{array}{l}\text { State of } \\
\text { Origin }\end{array}$ & Supplier & Type of Analysis \\
\hline 1 & $\begin{array}{l}\text { Multi-parameter } \\
\text { Tester (Water } \\
\text { Proof) }\end{array}$ & Eutech & $\mathrm{pH}$ Testr 30 & Singapore & $\begin{array}{l}\text { M/s Excel } \\
\text { International, } \\
\text { Kolkata, India }\end{array}$ & $\begin{array}{l}\text { Physical } \\
\text { parameter } \\
\text { characterization } \\
\text { (pH, Temp. } \\
\text { conductivity, } \\
\text { TDS) }\end{array}$ \\
\hline 2 & Turbidimeter & Eutech & TN-100 & Singapore & $\begin{array}{l}\text { M/s, Science } \\
\text { world, Nagpur, } \\
\text { India }\end{array}$ & Turbidity \\
\hline 3 & Photometer & Palintest & Photometer 7100 & UK & $\begin{array}{l}\text { M/s, } \\
\text { International } \\
\text { Trade Links } \\
\text { Instrumentation } \\
\text { Pvt. Ltd., } \\
\text { Kolkata, India. }\end{array}$ & $\begin{array}{l}\text { Chemical } \\
\text { Parameter } \\
\text { (Hardness, } \\
\text { Alkalinity, } \\
\text { Chloride, } \\
\text { Nitrate, } \\
\text { sulphate) }\end{array}$ \\
\hline 4 & $\begin{array}{l}\text { Atomic Absorption } \\
\text { Spectrophotometer }\end{array}$ & $\begin{array}{l}\text { Thermo } \\
\text { Fisher }\end{array}$ & $\begin{array}{l}\text { iCE3300 system } \\
\text { GFS33 }\end{array}$ & US & $\begin{array}{l}\text { M/s, Thermo } \\
\text { Fisher } \\
\text { Scientific India } \\
\text { Pvt. Ltd., } \\
\text { Kolkata. }\end{array}$ & $\begin{array}{l}\mathrm{Fe}, \mathrm{Al}, \mathrm{Cu}, \mathrm{Pb}, \\
\mathrm{Zn}, \mathrm{Cd}, \mathrm{As}\end{array}$ \\
\hline 5 & $\begin{array}{l}\text { Particle size } \\
\text { analyser }\end{array}$ & Malvern & Hydero2000MU & UK & $\begin{array}{l}\text { M/s, } \\
\text { Aimil Limited, } \\
\text { Kolkata. }\end{array}$ & $\begin{array}{l}\text { Size of coal \& } \\
\text { coal flocs }\end{array}$ \\
\hline 6 & $\begin{array}{l}\text { Thermogravimetric } \\
\text { analyser }\end{array}$ & $\begin{array}{l}\text { ELTRA } \\
\text { Elemental } \\
\text { Analyzers }\end{array}$ & $\begin{array}{l}\text { EltraTGA } \\
\text { Thermostep }\end{array}$ & Germany & $\begin{array}{l}\text { Verder } \\
\text { Scientific } \\
\text { Private Ltd., } \\
\text { Kolkata, India }\end{array}$ & $\begin{array}{l}\text { Proximate } \\
\text { analysis }\end{array}$ \\
\hline 7 & CHNS analyzer & German & $\begin{array}{l}\text { ElementarVario } \\
\text { EL-III, } \\
\text { S.No.-1101404 }\end{array}$ & India & $\begin{array}{l}\text { Elementar India } \\
\text { Pvt. Ltd., } \\
\text { Gurgaon, India }\end{array}$ & $\begin{array}{l}\text { Ultimate } \\
\text { Analysis }\end{array}$ \\
\hline 8 & Bomb calorimeter & LECO & AC-350 & USA & $\begin{array}{l}\text { IR Technology } \\
\text { Services Pvt. } \\
\text { Ltd., Kolkata, } \\
\text { India }\end{array}$ & GCV \& grade \\
\hline 9 & Thermal analyzer & NETZSCH, & Jupiter STA 449F3 & Germany & $\begin{array}{l}\text { NETZSCH } \\
\text { Technologies } \\
\text { India Pvt. Ltd. } \\
\text { Kolkata, India }\end{array}$ & $\begin{array}{l}\text { TG-DTA } \\
\text { analysis }\end{array}$ \\
\hline 10 & XRD analyzer & Rigaku & $\begin{array}{l}\text { Smart Lab Studio } \\
\text { IIx64x4.3.177.0 } \\
\text { IDNo.BD69000287- } \\
01\end{array}$ & Japan & $\begin{array}{l}\text { IR Technology } \\
\text { Services Pvt. } \\
\text { Ltd., Kolkata, } \\
\text { India }\end{array}$ & $\mathrm{XRD}$ analysis \\
\hline 11 & $\begin{array}{l}\text { FTIR } \\
\text { spectrophotometer }\end{array}$ & $\begin{array}{l}\text { Perkin } \\
\text { Elmer }\end{array}$ & Spectrum 2.0 & US & $\begin{array}{l}\text { Perkin Elmer } \\
\text { (India) Pvt Ltd., } \\
\text { Thane (MH), } \\
\text { India. }\end{array}$ & FTIR analysis \\
\hline 12 & $\begin{array}{l}\text { Zeta Meter } 4.0 \\
\text { with a } \\
\text { microprocessor }\end{array}$ & & Version 1.4 Rev 2c & Verginia & $\begin{array}{l}\text { M/s Orbit } \\
\text { Research } \\
\text { Associates Pvt. } \\
\text { Ltd., Delhi, } \\
\text { India }\end{array}$ & $\begin{array}{l}\text { Electrokinetic } \\
\text { measurements } \\
\text { (Zeta potential) }\end{array}$ \\
\hline
\end{tabular}


Table 4: Properties of the polymers

\begin{tabular}{|l|l|l|l|}
\hline Name & Telfloc3674F & Magna1011 & Nalco83370 $^{+}$ \\
\hline Type & Cationic & Anionic & Non-ionic \\
\hline Charge density & Medium to high charged & $\begin{array}{l}\text { Medium to high } \\
\text { charged }\end{array}$ & $\begin{array}{l}\text { Low to medium } \\
\text { charged }\end{array}$ \\
\hline $\begin{array}{l}\text { Molecular } \\
\text { Weight }\end{array}$ & Medium & High & Low \\
\hline Supplier & $\begin{array}{l}\text { Ion Exchange India (Ltd.), Patancheru, } \\
\text { India }\end{array}$ & BASF, India & NALCO, India \\
\hline
\end{tabular}

Table 5: The summary of the tests carried out their levels studied

\begin{tabular}{|c|c|c|c|c|c|}
\hline \multicolumn{6}{|c|}{ Variable studied } \\
\hline Sl No & Category & Pulp density, \% (w/w) & Floc Dosage, gpt & $\mathrm{pH}$ of Pulp & No. of Tests \\
\hline \multirow[t]{3}{*}{1} & \multirow[t]{3}{*}{ Telfloc3674F (Cationic) } & \multirow[t]{3}{*}{3} & $2,4,6,8$ & 8.72 & 4 \\
\hline & & & $2,4,6,8$ & 4.00 & 4 \\
\hline & & & $2,4,6,8$ & 11.0 & 4 \\
\hline \multirow[t]{3}{*}{2} & \multirow[t]{3}{*}{ Nalco-83370 ${ }^{+}$(Non-Ionic) } & \multirow[t]{3}{*}{3} & $2,4,6,8$ & 8.72 & 4 \\
\hline & & & $2,4,6,8$ & 4.00 & 4 \\
\hline & & & $2,4,6,8$ & 11.0 & 4 \\
\hline \multirow[t]{3}{*}{3} & \multirow[t]{3}{*}{ Magna1011 (Anionic) } & \multirow[t]{3}{*}{3} & $2,4,6,8$ & 8.72 & 4 \\
\hline & & & $2,4,6,8$ & 4.00 & 4 \\
\hline & & & $2,4,6,8$ & 11.0 & 4 \\
\hline \multicolumn{5}{|c|}{ Total Tests conducted } & 36 \\
\hline
\end{tabular}

\section{Figures}

Please see the supplementary files section to view the figures.

Figure 1

Please see the supplementary files section to view the figures.

\section{Supplementary Files}

This is a list of supplementary files associated with this preprint. Click to download.

- Figures.docx 